\title{
Article \\ Study on the Stability of the Electrical Connection of High-Temperature Pressure Sensor Based on the Piezoresistive Effect of P-Type SiC
}

\author{
Yongwei Li ${ }^{1,2}$, Ting Liang ${ }^{1, *}$, Cheng Lei ${ }^{1}$, Qiang Li ${ }^{1}$, Zhiqiang Li ${ }^{1}$, Abdul Ghaffar ${ }^{1}$ and Jijun Xiong ${ }^{1, *}$ \\ 1 Science and Technology on Electronic Test \& Measurement Laboratory, North University of \\ China, Taiyuan 030051, China; liyongwei27@163.com (Y.L.); leicheng@nuc.edu.cn (C.L.); \\ snjk08@163.com (Q.L.); lizhiqiangnuc@163.com (Z.L.); 92ghaffar@gmail.com (A.G.) \\ 2 Department of Automation, Taiyuan Institute of Technology, Taiyuan 030051, China \\ * Correspondence: liangtingnuc@163.com (T.L.); xiongjijun@nuc.edu.cn (J.X.)
}

Citation: Li, Y.; Liang, T.; Lei, C.; Li, Q.; Li, Z; Ghaffar, A.; Xiong, J. Study on the Stability of the Electrical Connection of High-Temperature Pressure Sensor Based on the Piezoresistive Effect of P-Type SiC. Micromachines 2021, 12, 216. https:// doi.org $/ 10.3390 / \mathrm{mi} 12020216$

Academic Editor: Ha Duong Ngo

Received: 16 January 2021

Accepted: 19 February 2021

Published: 21 February 2021

Publisher's Note: MDPI stays neutral with regard to jurisdictional claims in published maps and institutional affiliations.

Copyright: (c) 2021 by the authors. Licensee MDPI, Basel, Switzerland. This article is an open access article distributed under the terms and conditions of the Creative Commons Attribution (CC BY) license (https:/ / creativecommons.org/licenses/by/ $4.0 /)$.

\begin{abstract}
In this study, a preparation method for the high-temperature pressure sensor based on the piezoresistive effect of p-type $\mathrm{SiC}$ is presented. The varistor with a positive trapezoidal shape was designed and etched innovatively to improve the contact stability between the metal and $\mathrm{SiC}$ varistor. Additionally, the excellent ohmic contact was formed by annealing at $950{ }^{\circ} \mathrm{C}$ between $\mathrm{Ni} / \mathrm{Al} / \mathrm{Ni} / \mathrm{Au}$ and p-type $\mathrm{SiC}$ with a doping concentration of $10^{18} \mathrm{~cm}^{-3}$. The aging sensor was tested for varistors in the air of $25^{\circ} \mathrm{C}-600^{\circ} \mathrm{C}$. The resistance value of the varistors initially decreased and then increased with the increase of temperature and reached the minimum at $\sim 450{ }^{\circ} \mathrm{C}$. It could be calculated that the varistors at $\sim 100{ }^{\circ} \mathrm{C}$ exhibited the maximum temperature coefficient of resistance (TCR) of $\sim-0.35 \% /{ }^{\circ} \mathrm{C}$. The above results indicated that the sensor had a stable electrical connection in the air environment of $\leq 600^{\circ} \mathrm{C}$. Finally, the encapsulated sensor was subjected to pressure/depressure tests at room temperature. The test results revealed that the sensor output sensitivity was approximately $1.09 \mathrm{mV} / \mathrm{V} /$ bar, which is better than other SiC pressure sensors. This study has a great significance for the test of mechanical parameters under the extreme environment of $600{ }^{\circ} \mathrm{C}$.
\end{abstract}

Keywords: silicon carbide; pressure sensor; piezoresistive effect; mesa varistor; ohmic contact

\section{Introduction}

With the booming of control science and intelligent monitoring technology, the pressure sensor technology in extreme environments such as engines and oil drilling has received extensive attention from scholars [1,2]. Compared with capacitive, optical fiber, surface acoustic wave, and other types of sensors, piezoresistive pressure sensors have the advantages of the easiness of design configuration, small size, simple processing technology, and the wider linearity range [3-5]. Owing to the excellent piezoresistive effect of silicon ( $\mathrm{Si}$ ) and mature Si-based micro-electromechanical system (MEMS) processing technology, pressure sensors based on the Si-piezoresistive effect are currently the most commonly used. However, in a high-temperature environment above $500{ }^{\circ} \mathrm{C}$, Si materials will undergo plastic deformation after pressure and are easily corroded or oxidized, limiting the application of $\mathrm{Si}$ pressure sensors in extreme environments [6-8].

As the third-generation, wide-band gap semiconductor, silicon carbide $(\mathrm{SiC})$ has the advantages of the wide-band gap, high thermal conductivity, high mechanical strength, strong radiation resistance, and so on. It has been widely used to prepare sensors and power electronic devices working in extreme environments such as high temperature, high frequency, and high pressure [9-11]. What is noteworthy is that hexagonal $\mathrm{SiC}$ as bulk $\mathrm{SiC}$, such as $6 \mathrm{H}-$ and $4 \mathrm{H}-$, is considered the most promising semiconductor materials for the preparation of all $\mathrm{SiC}$ sensors working in high-temperature environment semiconductors $[12,13]$. The piezoresistive properties of SiC have attracted more and more attention 
from scholars, along with the development of SiC crystal growth technology, homogeneous epitaxy technology, and doping technology $[14,15]$. However, compared with the piezoresistive properties of $\mathrm{Si}$, the strain coefficient of $\mathrm{SiC}$ is about 5 times smaller and the temperature coefficient of gauge factor (TCGF) is larger, which leads to the generally lower sensitivity of pressure sensors based on the piezoresistive effect of silicon carbide. Robert S. Okojie et al. verified the significant piezoresistive effect of $6 \mathrm{H}-\mathrm{SiC}$ and prepared the high-temperature pressure sensor that could work at $600{ }^{\circ} \mathrm{C}$ in 2007. Nevertheless, due to the insufficient strain coefficient and excessive temperature coefficient of gauge factor (TCGF), the sensor's output sensitivity deteriorated seriously in the environment of more than $300^{\circ} \mathrm{C}$ [16-18]. In order to promote the application of $\mathrm{SiC}$ piezoresistive pressure sensors in high-temperature environments, some teams have turned their research interests to $4 \mathrm{H}-\mathrm{SiC}$.

In 2012, T. Akiyama et al. reported for the first time that the strain coefficient of n-type $4 \mathrm{H}-\mathrm{SiC}$ was approximately 20.8 [19]. In 2015, Robert S. Okojie prepared a pressure sensor based on the n-type $4 \mathrm{H}-\mathrm{SiC}$ piezoresistive effect that can work at $800{ }^{\circ} \mathrm{C}$. The sensor's output sensitivity gradually decreased when it was less $400^{\circ} \mathrm{C}$, increased when it was more significant than $400{ }^{\circ} \mathrm{C}$, and returned to where the values measured at $800^{\circ} \mathrm{C}$ were nearly equal to or higher than the room temperature values. However, the sensor's dynamic performance was poor, which may be caused by insufficient strain coefficient [20]. After that, Tuan-Khoa Nguyen et al. from Griffith University began to investigate the characterization of the p-type $4 \mathrm{H}-\mathrm{SiC}$ piezoresistive effect. The team experimentally confirmed for the first time that the strain coefficient of p-type $4 \mathrm{H}-\mathrm{SiC}$ was about 31.5 , which was 1.5 times of the strain coefficient of n-type $4 \mathrm{H}-\mathrm{SiC}$ [21]. Meanwhile, Li et al. from the North University of China also obtained similar results [22]. It is worth noting that the SiC epitaxial layer's square resistance in the references $[21,22]$ was about $22.9 \mathrm{k} \Omega / \square$ and $5.6 \mathrm{k} \Omega / \square$, respectively, which was too large for the preparation of sensors. Analysis showed the large square resistance was caused by the poor ohmic contact effect between metal and $\mathrm{SiC}$, consistent with the literature's viewpoint [23]. To the best of our knowledge, there are few articles on the design and fabrication of sensors based on the p-type $4 \mathrm{H}-\mathrm{SiC}$ piezoresistive effect.

In this paper, a pressure sensor based on the p-type $4 \mathrm{H}-\mathrm{SiC}$ piezoresistive effect was designed and prepared. In order to improve the stability of the electrical connection between the metal leads and varistors, a positive trapezoidal mesa resistor was innovatively proposed. Furthermore, $\mathrm{Ni} / \mathrm{Al} / \mathrm{Ni} / \mathrm{Au}$ and p-type silicon carbide $(\mathrm{SiC})$ with an aluminum doping concentration of $8.1 \times 10^{18} \mathrm{~cm}^{-3}$ formed good ohmic contact after annealing at $950{ }^{\circ} \mathrm{C}$ under vacuum for two minutes. The square resistance of the $\mathrm{SiC}$ epitaxial layer was about $448.5 \Omega$ and the contact resistivity was about $10^{-4} \Omega \cdot \mathrm{cm}^{2}$, measured using a rectangular transmission line model. The sensor chip was prepared according to the designed process flow, and varistors of the aging sensor were tested with the temperature. In the temperature range of $25^{\circ} \mathrm{C}-600{ }^{\circ} \mathrm{C}$, the varistors first decreased and then increased with the increase of temperature. At about $100{ }^{\circ} \mathrm{C}$, the temperature coefficient of resistance (TCR) reached a maximum of $-0.35 \% /{ }^{\circ} \mathrm{C}$, which proved that there was a stable electrical connection between metal and $\mathrm{SiC}$ mesa resistors. Finally, a pressure/depressure test was carried out on the encapsulated sensor at room temperature. The sensor output sensitivity was $~ 1.09 \mathrm{mV} / \mathrm{V} / \mathrm{bar}$, which was better than most of the $\mathrm{SiC}$ pressure sensors that have been reported. This research laid a technical foundation for the development of pressure sensors based on the p-type SiC piezoresistive effect.

\section{Materials and Methods}

\subsection{Sensor Design}

The pressure sensor based on the piezoresistive effect integrates four varistors into a pressure-sensitive diaphragm and connects them to be a Wheatstone bridge. When the environmental pressure changes, the varistors on the diaphragm change in proportion to the pressure and the pressure signal is detected by the output of the bridge circuit. The standard pressure-sensitive diaphragm includes square diaphragms, circular diaphragms, and 
island diaphragms with masses' block. With the difficulty of SiC MEMS processing, island diaphragms are generally not considered as pressure-sensitive diaphragms. According to the theory of elasticity, the diaphragm's maximum stress under the same size condition is 1.64 times larger than that of the round diaphragm [24,25]. Therefore, in this paper, the pressure sensor adopted the square pressure-sensitive diaphragm of $1000 \mu \mathrm{m} \times 1000 \mu \mathrm{m}$. The plane structure model of the square diaphragm is shown in Figure 1(a), which was supported on four sides. According to the thin plate theory [24], the deflection distribution on the square diaphragm under pressure can be expressed as Equation (1).

$$
\omega(x, y)=0.0213 \frac{16 p}{a^{4} D}\left(\frac{a^{2}}{4}-x^{2}\right)^{2}\left(\frac{a^{2}}{4}-y^{2}\right)^{2}
$$

where $\omega(x, y)$ is the deflection of any point on the diaphragm $(x=(-a / 2, a / 2), y=(-a / 2$, $a / 2)), p$ is the applied pressure, and $a$ is the edge length of the square diaphragm. D denotes the bending strength of the diaphragm, which can be expressed as Equation (2).

$$
D=E h^{3} / 12\left(1-v^{2}\right)
$$

where $E$ is the elastic modulus of the $\mathrm{SiC}, h$ is the thickness of the sensitive diaphragm, and $v$ is Poisson's ratio of the SiC. According to Equation (1), it can be deduced that the maximum deflection occurs at the center of the diaphragm $(x=0, y=0)$.
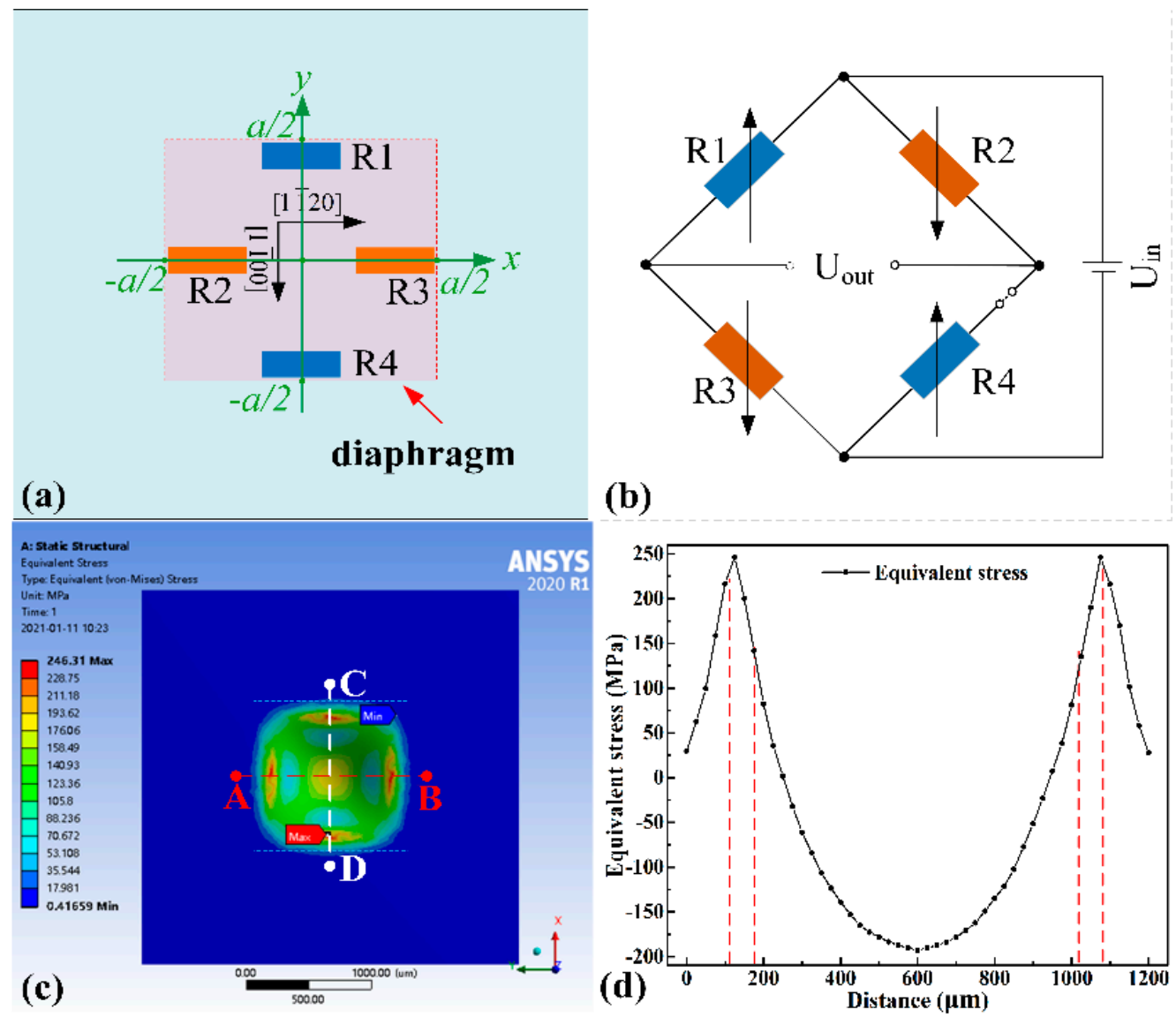

Figure 1. (a) Schematic diagram of sensor structure and varistor layout position. The diaphragm size is $1000 \mu \mathrm{m} \times 1000 \mu \mathrm{m} \times 45 \mu \mathrm{m}$ and the sensor chip size is $3300 \mu \mathrm{m} \times 3300 \mu \mathrm{m} \times 346 \mu \mathrm{m}$; (b) connection method of the varistors; (c) the finite element simulation results of $\mathrm{SiC}$ pressure-sensitive structure when the pressure of $1 \mathrm{MPa}$ is applied; (d) the stress distribution from path A to B, which is symmetric to path $\mathrm{C}$ to $\mathrm{D}$. 
The equivalent stress distribution on the square diaphragm under pressure can be expressed as Equation (3).

$$
\sigma(x, y)=0.5112 \frac{16 p(1-v)}{a^{4} h^{2}}\left[\left(3 x^{2}-\frac{a^{2}}{4}\right)\left(y^{2}-\frac{a^{2}}{4}\right)^{2}-\left(3 y^{2}-\frac{a^{2}}{4}\right)\left(x^{2}-\frac{a^{2}}{4}\right)^{2}\right]
$$

where $\sigma(x, y)$ is the equivalent stress of any point on the diaphragm. According to Equation (2), it can be deduced that the maximum equivalent stress occurs at the middle area of the edge of the diaphragm such as $(x=a / 2, y=0)$. The following is to design the diaphragm's thickness with a working range of $1 \mathrm{MPa}$, which needs to consider the linear principle and the anti-overload principle. The so-called linear principle means that the maximum deflection of the sensitive diaphragm must be less than $1 / 5$ of the diaphragm's thickness when the sensor is subjected to full-scale pressure to ensure that the diaphragm works in the linear region. The relationship between the maximum deflection of sensitive diaphragm, working range, and diaphragm thickness can be expressed as Equation (4).

$$
\omega_{\max }=\frac{0.0213 \times 12 \times\left(1-v^{2}\right) p_{\max } a^{4}}{16 \cdot E h^{3}}<\frac{h}{5}
$$

where $\omega_{\max }$ is the maximum deflection of the diaphragm after being pressured and $p_{\max }$ is the maximum working pressure of the sensor. The so-called anti-overload principle means that when the sensor is subjected to full-scale pressure, the maximum equivalent stress of the sensitive diaphragm must be less than $1 / 5$ of the yield stress of the $\mathrm{SiC}$ to prevent irreversible deformation of the sensor due to excessive pressure. The relationship between the maximum stress of the sensitive diaphragm and the working range and diaphragm size can be expressed as Equation (5).

$$
\sigma_{\max }=\frac{1.0224 \times(1-v) p_{\max } a^{2}}{4 \times h^{2}} \leq \frac{\sigma_{\mathrm{y}}}{5}
$$

where $\sigma_{\max }$ is the maximum equivalent stress on the surface of the pressure-sensitive diaphragm and $\sigma_{\mathrm{y}}$ is the yield stress of $\mathrm{SiC}$. Based on the above calculation results and process feasibility, the size of the pressure-sensitive diaphragm was designed to $1000 \mu \mathrm{m} \times 1000 \mu \mathrm{m} \times 45 \mu \mathrm{m}$ and the sensor chip size was $3300 \mu \mathrm{m} \times 3300 \mu \mathrm{m} \times 346 \mu \mathrm{m}$, as illustrated in Figure 1a.

Four varistors should be arranged in the stress concentration area of the sensitive diaphragm as far as possible to improve the sensor's output sensitivity. The sensor model was established via ANSYS (Pittsburgh, PA, USA) and the pressure of 1MPa was uniformly applied on the surface of the diaphragm. Based on the finite element simulation results, as shown in Figure 1c, the stress concentration area on the diaphragm's surface was distributed in the middle area of the edge of the diaphragm, which was consistent with theoretical calculations. Hence, the four $\mathrm{SiC}$ varistors with a size of $80 \mu \mathrm{m} \times 20 \mu \mathrm{m}, \mathrm{R} 1, \mathrm{R} 2$, $\mathrm{R} 3$, and R4, respectively, were arranged on the edge of the sensitive diaphragm, as shown in Figure $1 \mathrm{~b}$. What calls for special attention is that R1 and R4 were arranged perpendicular to the edge of the diaphragm, while R2 and R3 were arranged parallel to the edge. The four resistors were connected to form a semi-open-loop Wheatstone Bridge, as shown in Figure $1 \mathrm{~b}$. It was to facilitate the measurement of the resistance value of each resistor. When the uniform pressure was applied to the diaphragm's surface, the resistance value of R1 and R4 increased while the piezoresistance of R2 and R3 decreased, resulting in the output of the bridge changing in proportion to the pressure. Ideally, since the four varistors sizes were the same, the bridge was balanced and the output voltage was zero in the absence of pressure. When pressure was applied to the surface of the diaphragm, the resistance value of the varistors changed. Assuming that the four resistors' changes were uniform, the output of the bridge can be expressed as Equation (6).

$$
U_{\text {out }}=\frac{\Delta R}{R} U_{\text {in }}
$$


where $\Delta R / R$ is the rate of change of single varistor and $U_{\text {in }}$ is the bridge's input. It can be calculated so that the output sensitivity of the sensor is shown in formula (7).

$$
S=\frac{1}{P} \frac{\Delta R}{R}=\frac{1}{P} \frac{\Delta \rho}{\rho}=\frac{1}{P} \cdot \frac{G F}{E} \cdot \sigma_{\mathrm{a}}
$$

where $P$ is the pressure applied on the surface of the diaphragm, $\Delta \rho / \rho$ is the rate of change of resistivity, GF is the strain coefficient of the varistor, and $\sigma_{a}$ is the average stress of the varistor. When $G F$ takes 30, according to reference [21], the output sensitivity of the sensor can be calculated theoretically as $1.3 \mathrm{mV} / \mathrm{V} / \mathrm{bar}$.

\subsection{Sensor Preparation}

In this experiment, $\mathrm{n}$-type $4 \mathrm{H}-\mathrm{SiC}$ wafer with a doping concentration of $10^{14} \mathrm{~cm}^{-3}$ was used as the substrate, which was purchased from China Tianke Heda Co., Ltd. The thickness of the $\mathrm{SiC}$ substrate was $342 \mu \mathrm{m}$ and the diameter was 4 inches. The p-type epitaxial layer with a doping concentration of $10^{19} \mathrm{~cm}^{-3}$ and a thickness of $2 \mu \mathrm{m}$ was homogeneously grown on the silicon surface of the $\mathrm{SiC}$ substrate to prepare the varistors. There was an n-type buffer layer with a doping concentration of $10^{18} \mathrm{~cm}^{-3}$ and a thickness of $2 \mu \mathrm{m}$ between the p-type epitaxial layer and the substrate, which was to form a PN junction between the varistors and the substrate and prevent the current flow of the varistors from leakage to the substrate. The $\mathrm{SiC}$ homogeneous epitaxy process was realized via the chemical vapor deposition process in Dongguan Tianyu Semiconductor Co., Ltd.

The pressure sensor based on the piezoresistive effect of p-type $4 \mathrm{H}-\mathrm{SiC}$ was manufactured using the standard MEMS process, as shown in Figure 2, including the crucial processes such as varistors' etching, thermal oxidation, metal deposition, deep etching of pressure reference cavity, etc. Firstly, the $\mathrm{SiC}$ wafer with the p-type $4 \mathrm{H}-\mathrm{SiC}$ epitaxial layer was cleaned using a standard root cause analysis (RCA) process. In order to remove impurities and suspended chemical bonds on the surface of the wafer, it was thermally oxidized at $1100{ }^{\circ} \mathrm{C}$ for four hours in the thermal oxidation furnace (Qingdao Huaqi Technology Co., Ltd., Qingdao, China) and then the $\mathrm{SiO}_{2}$ was corroded away in the buffered oxide etch (BOE) solution. Secondly, adopting AZ4620 photoresist as a mask, reactive ion etching machine (RIE) was used to etch the positive trapezoidal mesa varistors. The etching height of the varistors was about $2 \mu \mathrm{m}$. In order to effectively control the height of varistors, the $\mathrm{SiC}$ etching rate should not be too fast. The $\mathrm{SiC}$ etching rate corresponding to the RIE etching parameters shown in Table 1 was about $69 \mathrm{~nm} / \mathrm{min}$.

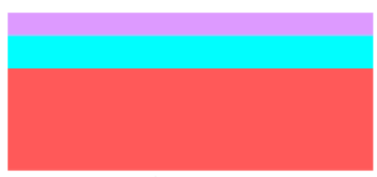

(a)

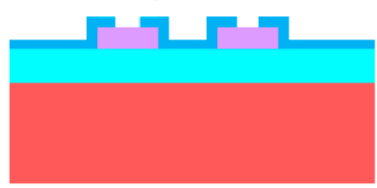

(d)

$\mathrm{SiC}$

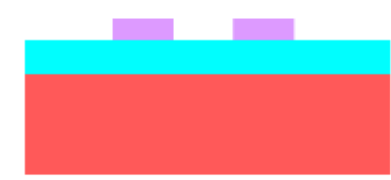

(b)

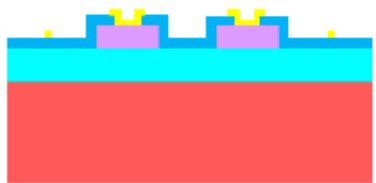

(e)

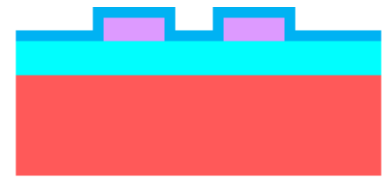

(c)

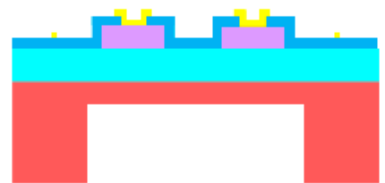

(f)

Figure 2. Process flow of sensor. (a) Structure diagram of SiC epitaxial wafer. (b) Varistors were shallowly etched using reactive ion etching machine (RIE). (c) The $\mathrm{SiO}_{2}$ was grown by thermal oxidation as an electrical isolating layer. (d) Ohmic contact holes were opened by wet corrosion of $\mathrm{SiO}_{2}$. (e) Metal electrodes were formed by metal deposition and metal stripping. (f) The pressure reference cavity of the sensor was deeply etched using inductively coupled plasma (ICP) machine. 
Table 1. Reactive ion etching machine (RIE) etching parameters of SiC.

\begin{tabular}{cc}
\hline Etching Parameters & Value \\
\hline Equipment type & RIE-10NR \\
Etching gas & Mixture of $\mathrm{SF}_{6}$ and $\mathrm{O}_{2}$ \\
Gas flow & $\mathrm{SF}_{6} 40 \mathrm{sccm}, \mathrm{O}_{2} 10 \mathrm{sccm}$ \\
Etching power & $200 \mathrm{~W}$ \\
Chamber pressure & $4 \mathrm{~Pa}$ \\
\hline
\end{tabular}

What is worth mentioning was that the height of the varistors should be slightly larger than the thickness of the epitaxial layer, which is to ensure absolute electrical separation between each varistor. Therefore, it was necessary to test the p-type epitaxial layer's thickness through secondary ion mass spectrometry (SIMS) before etching the mesa varistors. Thirdly, in order to ensure insulation between the metal lead and the SiC substrate, thermal oxidation was again used to grow the $\mathrm{SiO} 2$ insulation layer on the the wafer's surface. Fourthly, adopting the AZ6130 photoresist as the mask, the oxide layer at both ends of the varistors was corroded away in the BOE solution to open the metal/SiC ohmic contact hole. Fifthly, the metal film of $20 \mathrm{~nm} \mathrm{Ni} / 100 \mathrm{~nm} \mathrm{Al} / 10 \mathrm{~nm} \mathrm{Ni} / 200 \mathrm{~nm}$ $\mathrm{Au}$ was deposited by the magnetron sputtering equipment (Denton Vacuum Equipment Co., Ltd., Denton, TX, USA) after the lithography process patterned the metal electrode leads. The metal electrode was prepared by stripping the excess metal film in an acetone solution. It is worth noting that the use of oxygen plasma to etch the wafer's surface before sputtering the metal not only increased the adhesion between the metal and $\mathrm{SiC}$, but also contributed to the formation of the ohmic contact. Sixthly, the nickel mask of $\sim 15 \mu \mathrm{m}$ was prepared by electroplating process on the back of the wafer. Then the wafer was cut into $2 \mathrm{~cm} \times 2 \mathrm{~cm}$ pieces, by DISCO DAD322 (an Automatic Dicing saw) (Disco Corporation, Tokyo, Japan), which were used to etch the pressure reference cavity by inductively coupled plasma (ICP) GDE C200 (North Microelectronics Company, Beijing, China). The parameters of the inductively coupled plasma (ICP) etching SiC are shown in Table 2 and the corresponding etching rate was $\sim 1.4 \mu \mathrm{m} / \mathrm{min}$. The pressure reference cavity was prepared by ICP etching for about $215 \mathrm{~min}$, as illustrated in Figure 3d. As can be seen from the scanning electron microscope (SEM) image of the chamber's sidewall shown in Figure 3e, the depth of the pressure chamber was about $301 \mu \mathrm{m}$, the thickness of the pressure diaphragm was about $45.1 \mu \mathrm{m}$, and the verticality of the sidewall was satisfactory.

Table 2. ICP etching parameters of SiC.

\begin{tabular}{cc}
\hline Etching Parameters & Value \\
\hline Equipment type & $\mathrm{ICP}$ GDE C200 \\
Etching gas & Mixture of $\mathrm{SF}_{6} / \mathrm{O}_{2} / \mathrm{Ar}_{2}$ \\
Gas flow & $\mathrm{SF}_{6} 180 \mathrm{sccm}, \mathrm{O}_{2} 40 \mathrm{sccm}, \mathrm{Ar}_{2} 20 \mathrm{sccm}$ \\
Etching power & $\mathrm{RF} 800 \mathrm{~W}, \mathrm{ICP} 2500 \mathrm{~W}$ \\
Chamber pressure & $5 \mathrm{mTorr}$ \\
\hline
\end{tabular}

According to the above technological process, the pressure sensor chip was prepared and the wafer was cut into individual chip using DISCO DAD322, as shown in Figure 3. Then, the annealing experiment was performed by using a rapid thermal processing furnace (Beijing East Star Institute of Applied Physics, Beijing, China) to explore the annealing parameters for forming the good ohmic contact between metal and p-type SiC. After that, the resistance values of the varistors were tested at $25^{\circ} \mathrm{C}$ to $600{ }^{\circ} \mathrm{C}$ to verify the stability of the ohmic contact between the metal and $\mathrm{SiC}$, as well as the reliability of the electrical connection between metal leads and the mesa varistors in the high-temperature environment. Finally, the wire bonding process was used for packaging the pressure sensor chip and the base, and the performance of the sensor was tested at room temperature. 


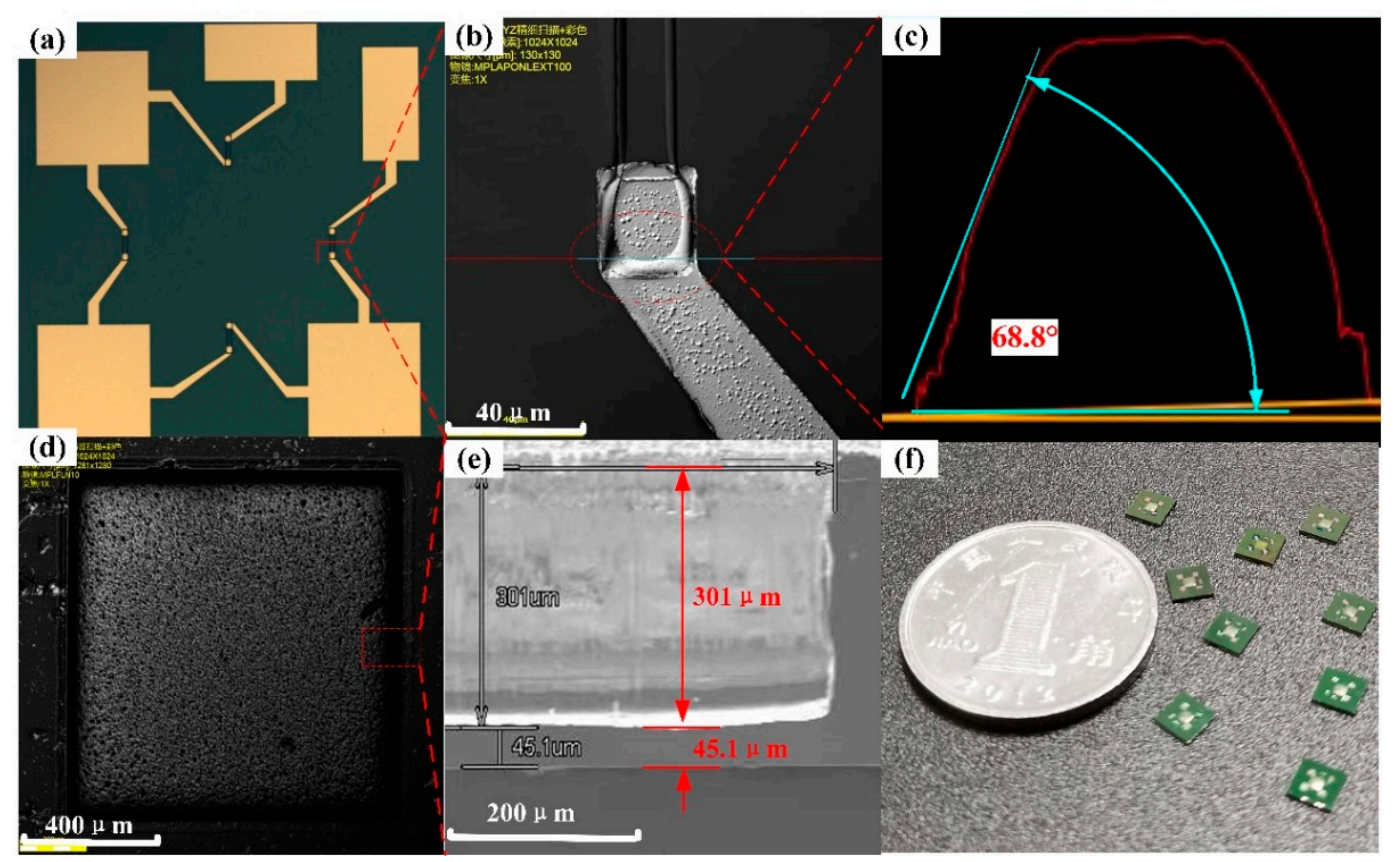

Figure 3. Diagram of sensor structure. (a) Front view of a single sensor chip. (b) The positive trapezoidal mesa resistor with metal lead. (c) Sidewall perpendicularity of mesa resistor. (d) Sensor pressure reference chamber image. (e) SEM image of the sidewall of pressure reference chamber. (f) Sensor chip sample.

\section{Results and Discussion}

The p-type SiC epitaxial layer was patterned and then etched to prepare varistors, whose height was determined by the epitaxial layer's actual thickness. More importantly, the quality of the epitaxial layer played a decisive role in the sensor's performance. The Invial laser Raman spectrum analyzer was employed to scan the $\mathrm{SiC}$ substrate and the epitaxial layer. The crystal quality of the epitaxial layer was judged by comparing the spectral results. An Ar+ atomic laser with a power of $5 \mathrm{~mW}$ and a wavelength of $532 \mathrm{~nm}$ was used as the test system's light source. After excitation, the laser was incident perpendicularly to the sample's surface, and then the backscattered light was collected and analyzed via computer. The measured scattering spectra of the $4 \mathrm{H}-\mathrm{SiC}$ substrate and epitaxial layer are shown in Figure 4a. It was observed that the substrate's characteristic peaks were consistent with the epitaxial layer, confirming that the epitaxial layer belonged to the $4 \mathrm{H}-\mathrm{SiC}$ crystal phase and had good quality. After that, the doping concentration and thickness of the epitaxial layer were tested using SIMS. The SIMS pattern is exhibited in Figure $4 \mathrm{~b}$. It was found that the concentration of doped aluminum in the epitaxial layer was $\sim 8.1 \times 10^{18} / \mathrm{cm}^{3}$ and the thickness of the epitaxial layer was $\sim 1.86 \mu \mathrm{m}$. Therefore, the height of the mesa varistors was designed to be $2.0 \mu \mathrm{m}$. The positive trapezoidal varistors were obtained by RIE etching for $29 \mathrm{~min}$, as shown in Figure 3b, and the sidewall perpendicularity of the mesa resistor was about $68.8^{\circ}$, as shown in Figure 3c, which was induced by controlling the topography of the photoresist mask. The angled mesa resistor increased the contact area between the metal lead and the $\mathrm{SiC}$, improving the connection stability.

Generally, Ti/Al metal system is used to form an ohmic contact with p-type SiC, whereas it cannot be used in harsh environments because aluminum is easily oxidized and has a low melting point. Therefore, gold was deposited on the surface of $\mathrm{Al}$ as a protective layer. We employed $20 \mathrm{~nm} \mathrm{Ni} / 100 \mathrm{~nm} \mathrm{Al}$ as the ohmic contact layer, $20 \mathrm{~nm}$ $\mathrm{Ni}$ as the isolation layer between metals, and $\mathrm{Au}$ as the electrode layer, which not only avoided oxidation of the metal electrode, but also facilitated wire bonding with external circuits. The metal electrode of the sensor is shown in Figure 3a. In order to form a good ohmic contact between the metal and $\mathrm{SiC}$ varistor, the sensor chip was annealed under different conditions. In this experiment, the sensor samples were quickly annealed in 
a vacuum environment for $2 \mathrm{~min}$ at $650{ }^{\circ} \mathrm{C}, 750{ }^{\circ} \mathrm{C}, 850{ }^{\circ} \mathrm{C}$, and $950{ }^{\circ} \mathrm{C}$. The curve of annealing temperature with time and the current-voltage characteristic curve at both ends of the varistor is shown in Figure 5, which was mesured by semiconductor parameter analyzer (Keithley, Cleveland, OH, USA). As can be seen in Figure 5b, when the annealing temperature was $950^{\circ} \mathrm{C}$, an excellent ohmic contact was formed. Using the rectangular transmission line model test, the square resistance and the specific contact resistivity of the $\mathrm{SiC}$ epitaxial layer were $448.5 \Omega$ and $10^{-4} \Omega \cdot \mathrm{cm}^{2}$, respectively.
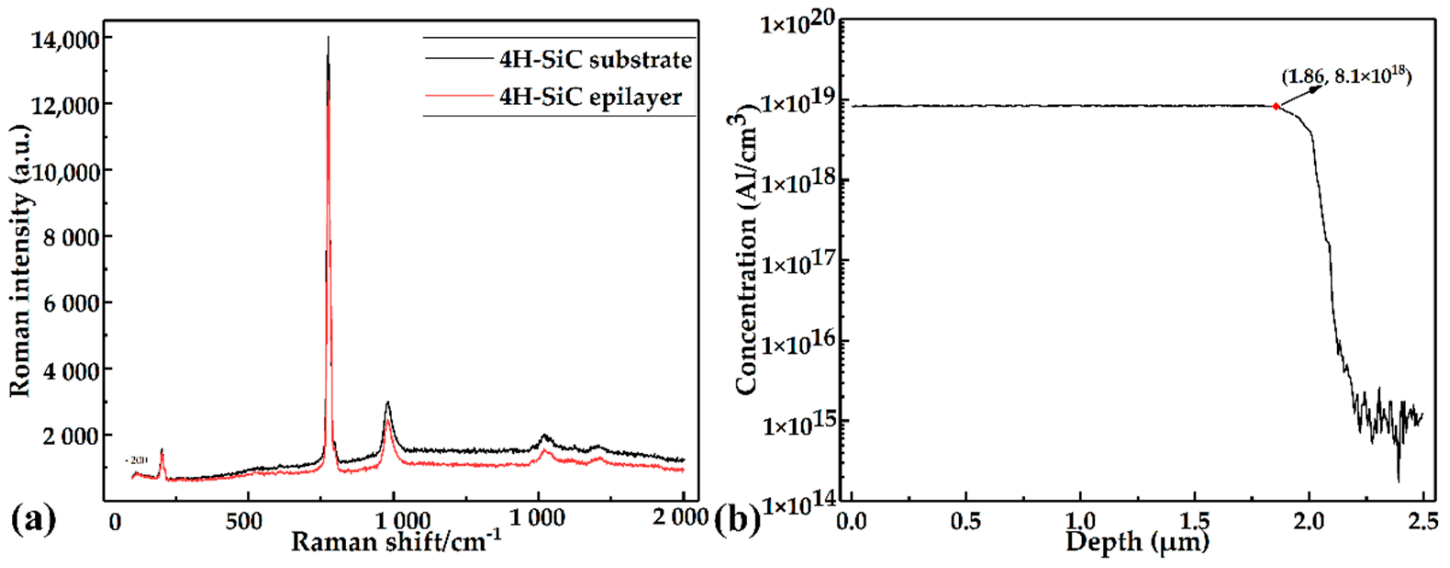

Figure 4. Characterization test of $\mathrm{SiC}$ epitaxial layer. (a) Raman spectra of epitaxial layer and substrate. (b) Secondary ion mass spectrometry (SIMS) pattern of the aluminum element in the epitaxial layer.
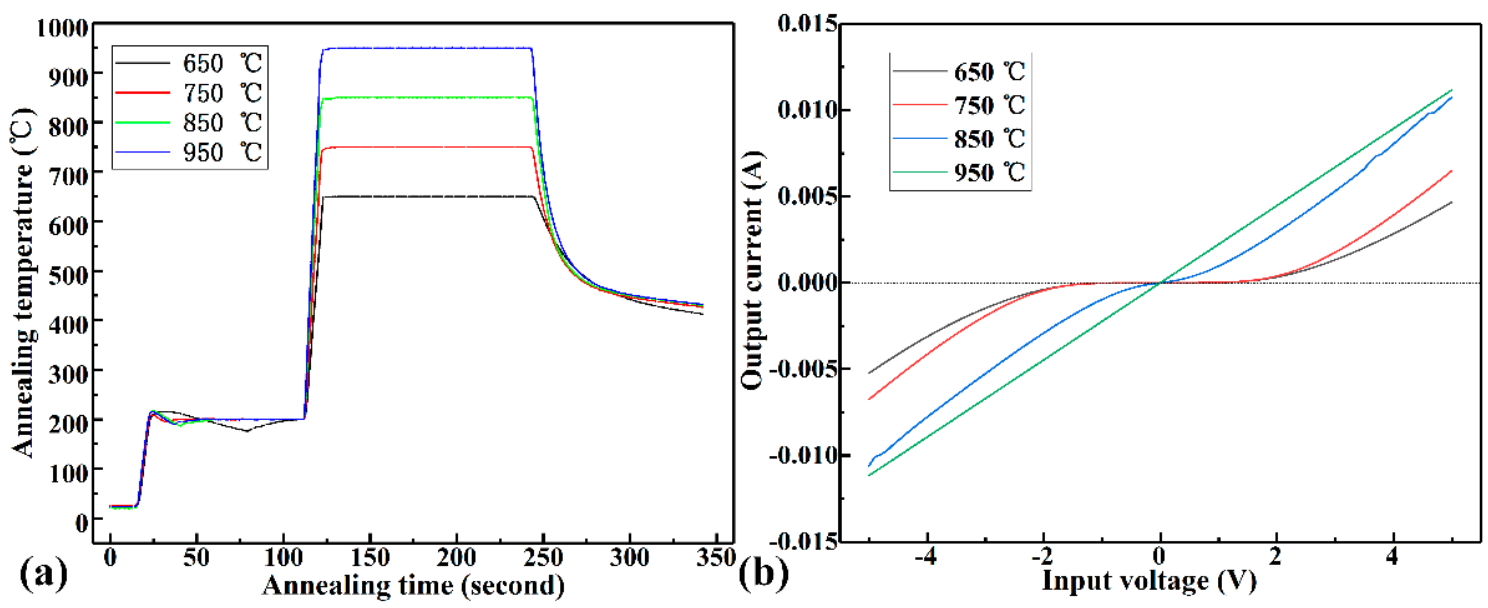

Figure 5. Ohmic contact test of SiC. (a) Annealing time-temperature curve. (b) The relationship between voltage and current at both ends of the resistor under different annealing conditions.

In order to verify the stability of the metal/SiC ohmic contact and the reliability of the electrical connection between the metal lead and the mesa varistor in the high-temperature environment, the varistors of the sensor were measured within the temperature range of $25^{\circ} \mathrm{C}$ to $600{ }^{\circ} \mathrm{C}$. The test equipment mounted by us consisted of a temperature console, two probe consoles, a microscope, and a digital multimeter, as shown in Figure 6a. It is worth noting that the sensor samples were aged in a nitrogen atmosphere of $300{ }^{\circ} \mathrm{C}$ for $20 \mathrm{~h}$ before the resistances were tested. The resistance values of four varistors measured at room temperature were $\mathrm{R} 1=1.75 \mathrm{k} \Omega, \mathrm{R} 2=1.70 \mathrm{k} \Omega, \mathrm{R} 3=1.86 \mathrm{k} \Omega$, and $\mathrm{R} 4=1.79 \mathrm{k} \Omega$, respectively. Then, in the temperature range of $50{ }^{\circ} \mathrm{C}$ to $600{ }^{\circ} \mathrm{C}$, the varistors' change was tested by increasing/decreasing the temperature in steps of $50^{\circ} \mathrm{C}$. We read the multimeter data in the heating test experiment after holding each temperature point for $10 \mathrm{~min}$. Furthermore, the lowering temperature test was carried out under natural cooling conditions. After 
averaging the two test results, the resistance value curve with temperature was plotted, as shown in Figure 6b. It can be seen from the test results that the stable transmission of electrical signals was achieved at temperatures from $25^{\circ} \mathrm{C}$ to $600{ }^{\circ} \mathrm{C}$, verifying the good connection between the metal lead and the mesa resistance. Additionally, the varistors resistance value obtained by increasing/decreasing the temperature tests was consistent, which implies a stable ohmic contact between the metal and the p-type $4 \mathrm{H}-\mathrm{SiC}$. Additionally, the TCR is a measure of the resistance changes with temperature, which is a pivotal parameter to determine the sensor's ability to be used in high-temperature or low-temperature environments [26]. TCR can be expressed as Equation (8).

$$
T C R=\frac{1}{R_{0}} \frac{R_{t}-R_{0}}{T-T_{0}}
$$

where $R_{0}(\Omega)$ is the resistance value at room temperature environment, $R_{\mathrm{t}}(\Omega)$ is the resistance value at the operation temperature, $T\left({ }^{\circ} \mathrm{C}\right)$ is the operating temperature, and $T_{0}$ $\left({ }^{\circ} \mathrm{C}\right)$ is the room temperature. According to the test results, the average TCR of the four p-type $4 \mathrm{H}-\mathrm{SiC}$ varistors with the doping concentration of $8.1 \times 10^{18} \mathrm{~cm}^{-3}$ in the range of $25{ }^{\circ} \mathrm{C}-600{ }^{\circ} \mathrm{C}$ can be calculated as shown in Table 3 .
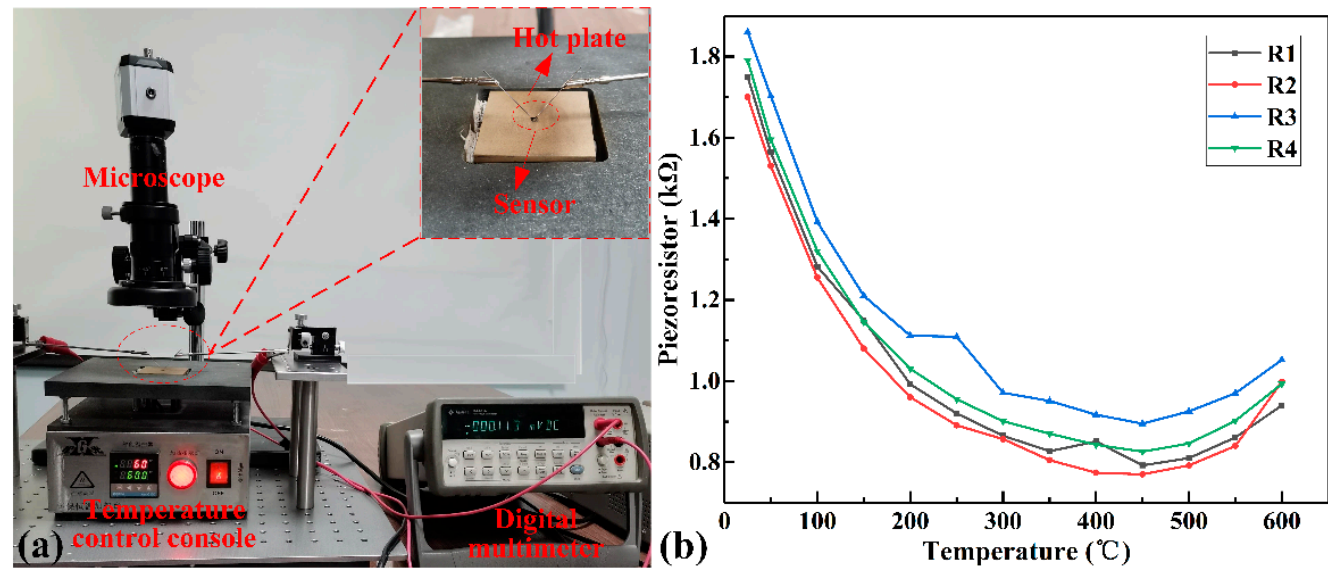

Figure 6. (a) Temperature control probe platform; (b) The variation curve of the varistors' value with temperature.

Table 3. Temperature coefficient of resistance (TCR) of p-type SiC.

\begin{tabular}{ccccccc}
\hline Temperature $/\left({ }^{\circ} \mathrm{C}\right)$ & 100 & 200 & 300 & 400 & 500 & 600 \\
\hline TCR $\left(\% /{ }^{\circ} \mathrm{C}\right)$ & -0.35 & -0.24 & -0.18 & -0.14 & -0.11 & -0.08 \\
\hline
\end{tabular}

In combination with Figure $6 \mathrm{~b}$, it was found that the resistance decreased with the temperature increasing at less than $400{ }^{\circ} \mathrm{C}$, indicating that the resistance was primarily determined by the degree of ionization of impurities below $400{ }^{\circ} \mathrm{C}$. When the temperature exceeded $500{ }^{\circ} \mathrm{C}$, the resistance increased with the increased temperature, indicating that lattice scattering played a significant role. Moreover, it was estimated that the impurities were entirely ionized between $400{ }^{\circ} \mathrm{C}$ and $500{ }^{\circ} \mathrm{C}$.

Next, the air tightness of the encapsulated sensor was tested by helium mass spectrometry. The sample was placed in a helium pressure chamber and kept under $600 \mathrm{KPa}$ pressure for $2 \mathrm{~h}$. The helium leakage rate was tested in the helium mass spectrometer's sealed chamber to be $1.9 \times 10^{-9} \mathrm{~Pa} \cdot \mathrm{m}^{3} / \mathrm{s}$, meeting the requirements of most pressure sensors. The four varistors of the sensor were connected to a four-arm Wheatstone bridge and the 5-V input voltage was supplied using a direct-current (DC) power supply (Gwinstek, Taiwan). By increasing/decreasing the pressure in a step of $100 \mathrm{KPa}$ within the pressure range of $0-1 \mathrm{MPa}$, the sensor's output voltage was tested with a high-precision multimeter (Agilent Technologies Inc, Palo Alto, CA, USA). When the applied pressure 
reached $1 \mathrm{MPa}$, the backstroke test started to execute. The test equipment and the test results are inllustrated in Figure 7. Figure $7 \mathrm{~b}$ indicates that the sensor's output sensitivity was approximately $1.09 \mathrm{mV} / \mathrm{V} /$ bar at room temperature, which is better than the reported $\mathrm{SiC}$ pressure sensor [27-30]. The above experimental results confirmed that the pressure sensor based on the piezoresistive effect of p-type $\mathrm{SiC}$ has the potential to be applied in extreme harsh environments.
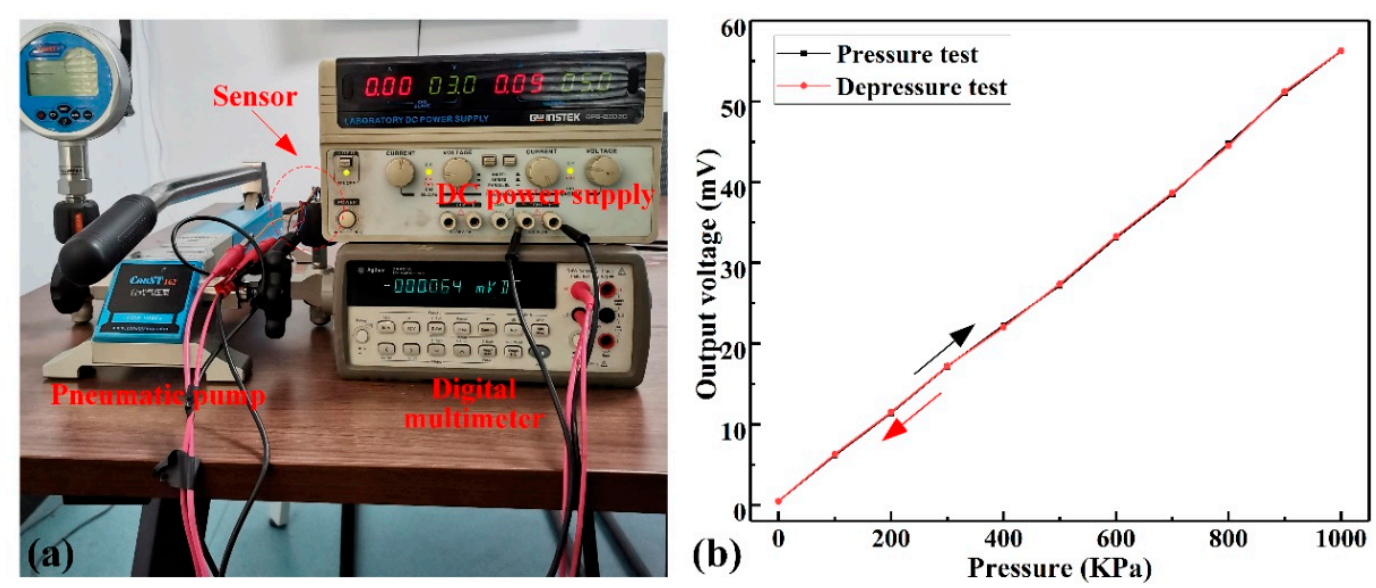

Figure 7. Performance test of the sensor at room temperature. (a) Pressure measuring system at room temperature. (b) The curve of output voltage as a function of pressure.

\section{Conclusions}

In this work, a high-temperature pressure sensor based on the piezoresistive effect of p-type $\mathrm{SiC}$ was designed and fabricated. In order to improve the stability of the electrical connection of sensor chips, the positive trapezoidal varistor was proposed. Using $\mathrm{Ni} / \mathrm{Al} / \mathrm{Ni} / \mathrm{Au}$ as the metal system, the excellent ohmic contact was formed with p-type $\mathrm{SiC}$ annealed at $950^{\circ} \mathrm{C}$ for $2 \mathrm{~min}$ in a vacuum environment. After the sensor chip was aged at $300^{\circ} \mathrm{C}$ for $20 \mathrm{~h}$ in the nitrogen environment, the varistors were measured at $25^{\circ} \mathrm{C}-600^{\circ} \mathrm{C}$ to confirm that the mesa varistors had reliable electrical connection performance at less than $\leq 600{ }^{\circ} \mathrm{C}$. Finally, the encapsulated sensor chip was tested at room temperature for pressure and depressure. The test results indicated that the output sensitivity of the sensor reached $\sim 1.09 \mathrm{mV} / \mathrm{V} /$ bar. This study provides a technical foundation for the application of $\mathrm{SiC}$ pressure sensors in a high-temperature environment. The sensor's flip-chip packaging method and the pressure/decompression test at $25^{\circ} \mathrm{C} \sim 600^{\circ} \mathrm{C}$ will be explored to promote further the development of $\mathrm{SiC}$ piezoresistive pressure sensors suitable for harsh environments.

Author Contributions: The work presented in this paper was a collaboration of all authors. Conceptualization, Y.L. and Q.L.; methodology, Y.L., T.L., and J.X.; validation, C.L. and J.X.; investigation and resources, Y.L.; data curation, Q.L. and Z.L.; writing-original draft preparation, Y.L., Q.L., and A.G.; writing-review and editing, Y.L. All authors have read and agreed to the published version of the manuscript.

Funding: This work was supported in part by the Natural Science Foundation of China under Grant 51935011, in part by the Key Research and Development Project of Shanxi Province under Grant 201903D121123, and in part by the Central Government Guides Local Science and Technology Development Fund Projects under Grant YDZX20201400001664, in part by the Science and Technology Innovation Project of Colleges and Universities in Shanxi Province under Grant 2020L0627.

Conflicts of Interest: The authors declare no conflict of interest. 


\section{References}

1. Senesky, D.G.; Jamshidi, B.; Cheng, K.B.; Pisano, A. Harsh Environment Silicon Carbide Sensors for Health and Performance Monitoring of Aerospace Systems: A Review. IEEE Sensors J. 2009, 9, 1472-1478. [CrossRef]

2. Gungor, V.C.; Hancke, G.P. Industrial Wireless Sensor Networks: Challenges, Design Principles, and Technical Approaches. IEEE Trans. Ind. Electron. 2009, 56, 4258-4265. [CrossRef]

3. Godovitsyn, I.V.; Amelichev, V.V.; Ankov, V.V. A high sensitivity surface-micromachined pressure sensor. Sensor Actuat. A Phys. 2013, 201, 274-280. [CrossRef]

4. Wang, J.; Chuai, R.; Yang, L.; Dai, B. A surface micromachined pressure sensor based on polysilicon nanofilm piezoresistors. Sensor Actuat. A Phys. 2015, 228, 75-81. [CrossRef]

5. Hoang-Phuong, P.; Karen, M.D.; Tuan-Khoa, N.; Chapin, C.; Toan, D.; Miller, R.; Han, J.; Alan, I.; Senesky, D.; Viet, D. Characterization of the piezoresistance in highly doped p-type 3C-SiC at cryogenic temperatures. RSC Adv. 2018, 8, 29976-29979.

6. Nguyen, T.K.; Phan, H.P.; Dinh, T.; Foisal, A.; Nguyen, N.; Dao, D. High-temperature tolerance of piezoresistive effect in p-4H-SiC for harsh environment sensing. J. Mater. Chem. C. 2018, 6, 1-5. [CrossRef]

7. Ha-Duong, N.; Biswaijit, M.; Oswin, E.; Lang, K. Advanced Liquid-Free, Piezoresistive, SOI-Based Pressure Sensors for Measurements in Harsh Environments. Sensors 2015, 15, 20305-20315.

8. Sheeparamatti, B.G.; Balavalad, K.B. Fabrication and characterization of polysilicon -on -insulator (PolySOI) and a-SOI based micro piezoresistive pressure sensor for harsh environment applications. Microsyst. Technol. 2019, 25, 4119-4133. [CrossRef]

9. Jegal, J.H.; Kwon, M.; Oh, C.Y.; Kim, K.; Lee, J. Implementation of three-phase four-leg inverter using SiC MOSFET for UPS applications. J. Power Electron. 2020, 21, 103-112. [CrossRef]

10. Kumar, V.; Verma, J.; Maan, A.S.; Akhtar, J. Epitaxial 4H-SiC based Schottky diode temperature sensors in ultra-low current range. VACUUM 2020, 182, 109590. [CrossRef]

11. Middelburg, L.M.; Zeijl HW, V.; Vollebregt, S.; Morana, B.; Zhang, G. Toward a Self-Sensing Piezoresistive Pressure Sensor for all-SiC Monolithic Integration. IEEE Sensors J. 2020, 20, 11265. [CrossRef]

12. Wu, C.H.; Zorman, C.A.; Mehregany, M. Fabrication and testing of bulk micromachined silicon carbide piezoresistive pressure sensors for high temperature applications. IEEE Sensors J. 2006, 6, 316-324.

13. Phan, H.P.; Dao, D.V.; Nakamura, K.; Nguyen, N. The Piezoresistive Effect of SiC for MEMS Sensors at High Temperatures: A Review. J. Microelectromech. S. 2015, 24, 1663-1677. [CrossRef]

14. Barlian, A.A.; Park, W.T.; Mallon, J.R.J.; Rastegar, A.; Pruitt, B. Review: Semiconductor Piezoresistance for Microsystems. P. IEEE 2009, 97, 513-552. [CrossRef] [PubMed]

15. Phan, H.P.; Dinh, T.; Kozeki, T.; Kozeki, T.; Qamar, A.; Namazu, T.; Dimitrijev, S.; Nam-Trung, N.; Dao, D. Piezoresistive effect in p-type 3C-SiC at high temperatures characterized using Joule heating. Science 2016, 6, 28499. [CrossRef] [PubMed]

16. Okojie, R.S.; Ned, A.A.; Kurtz, A.D.; Carr, W.N. Characterization of highly doped n- and p-type 6H-SiC piezoresistors. Electron Devices. IEEE T. Electron. Dev. 1998, 45, 785-790. [CrossRef]

17. Alexander, A.N.; Anthony, D.K.; Glenn, B.; Fawzia, M.; Stefanescu, S. Improved SiC Leadless Pressure Sensors for High Temperature, Low and High Pressure Applications. In Proceedings of the Twenty-First Transducer Workshop, Lexington, MD, USA, 22-23 June 2004.

18. Okojie, R.S. STable $600{ }^{\circ} \mathrm{C}$ Silicon Carbide MEMS Pressure Transducers. In Proceedings of the Sensors and Systems for Space Applications, Orlando, FL, USA, 3 May 2007.

19. Akiyama, T.; Briand, D.; De Rooij, N.F. Design-dependent gauge factors of highly doped n-type 4 H-SiC piezoresistors. J. Micromech. Microeng. 2012, 22, 085034. [CrossRef]

20. Okojie, R.S.; Lukco, D.; Nguyen, V.; Savrun, E. 4H-SiC Piezoresistive Pressure Sensors at $800{ }^{\circ} \mathrm{C}$ with Observed Sensitivity Recovery. IEEE Electr. Device L. 2015, 36, 174-176. [CrossRef]

21. Nguyen, T.K.; Phan, H.P.; Dinh, T.; Han, J.; Dimitrijev, S.; Tanner, P.; Foisal, A.; Zhu, Y.; Nguyen, N.; Dao, D. Experimental Investigation of Piezoresistive Effect in p-type 4H-SiC. IEEE Electr. Device L. 2017, 38, 955-958. [CrossRef]

22. Yongwei, L.; Ting, L.; Cheng, L.; Yingping, H.; Wangwang, L.; Zhiqiang, L.; Abdul, G.; Qiang, L.; Jijun, X. Quantitative Analysis of Piezoresistive Characteristic Based on a P-type 4H-SiC Epitaxial Layer. Micromachines 2019, 10, 629-637.

23. Ngo, H.D.; Mackowiack, P.; Grabbert, N.; Weiland, T.; Lang, K. The Roadmap for Development of Piezoresistive Micro Mechanical Sensors for Harsh Environment Applications. In Proceedings of the 2017 Eleventh International Conference on Sensing Technology (ICST), Sydney, Australia, 4-6 December 2017.

24. Nguyen, T.K.; Phan, H.P.; Dinh, T.; Karen, D.; Abu Riduan Md, F.; Debbie, S.; Nguyen, N.; Viet, D. Highly sensitive 4H-SiC pressure sensor at cryogenic and elevated temperatures. Mater. Design 2018, 156, 441-445. [CrossRef]

25. Kanda, Y.; Yasukawa, A. Optimum design considerations for silicon piezoresistive pressure sensors. Sensor Actuat. A Phys. 1997, 62, 539-542. [CrossRef]

26. Shor, J.S.; Bemis, L.; Kurtz, A.D. Characterization of monolithic n-type 6H-SiC piezoresistive sensing elements. IEEE T. Electron. Dev. 1994, 41, 661-665. [CrossRef]

27. Wu, C.H.; Stefanescu, S.; Kuo, H.I.; Zorman, C.; Mehregany, M. Fabrication and Testing of Single Crystalline 3C-SiC Piezoresistive Pressure Sensors. In Proceedings of the 11th International Conference on Solid-State Sensors and Actuators, Munich, Germany, 10-14 June 2001. 
28. Wieczorek, G.; Schellin, B.; Obermeier, E.; Fagnani, G. SiC Based Pressure Sensor for High-Temperature Environments. In Proceedings of the Sensors 2007 IEEE, Atlanta, GA, USA, 28-31 October 2007.

29. Fragaa, M.A.; Furlan, H.; Massia, M.; Oliveiraa, I.; Koberstein, L. Fabrication and characterization of a SiC/SiO $2 / \mathrm{Si} \mathrm{piezoresistive}$ pressure sensor. Procedia. Eng. 2010, 5, 609-612. [CrossRef]

30. Terunobu, A.; Danick, B.; Nico, F. Piezoresistive n-type 4H-SiC Pressure Sensor with Membrane Formed by Mechanical Milling. In Proceedings of the 2011 IEEE, Limerick, Ireland, 28-31 October 2011. 